Revista Brasileira de Agricultura Irrigada v.5, $\mathrm{n}^{\circ} .3$, p153- 164. , 2011

ISSN 1982-7679 (On-line)

Fortaleza, CE, INOVAGRI - http://www.inovagri.org.br

Protocolo 053.11 - 01/03/2011 Aprovado em 20/09/11

\title{
EFEITO DE LÂMINAS DE IRRIGAÇÃO E DOSES DE PBZ NA MICROFAUNA DO SOLO CULTIVADO COM MANGUEIRA CV. HADEN NO NORTE DE MINAS GERAIS
}

João Batista Ribeiro da Silva Reis ${ }^{1}$, Alniusa Maria de Jesus ${ }^{2}$, Mário Sérgio Carvalho Dias ${ }^{3}$, Daniel Philipe Veloso Leal ${ }^{4}$

${ }^{1}$ Engenheiro Agrícola, D.Sc., Pesquisador U. R. EPAMIG NM, Caixa Postal 12, CEP 39525-000 Nova Porteirinha-

MG, jbrsreis@epamig.br

${ }^{1}$ Bióloga, Pós-Doc., Pesquisadora U.R. EPAMIG NM, alniuza@epamig.br

${ }^{1}$ Engenheiro Agrônomo, D.Sc., Pesquisador U.R. EPAMIG SM, mariodias@epamig.br

${ }^{1}$ Mestrando em Irrigação e Drenagem, ESALQ, USP, philipeveloso10@yahoo.com.br.

RESUMO: O presente trabalho tem como objetivo avaliar diferentes lâminas de irrigação e doses de um regulador de crescimento na população microbiana do solo na cultura da manga cv. Haden no Norte de Minas Gerais. O experimento foi conduzido em delineamento inteiramente casualizado consistindo de 16 tratamentos com 3 repetições, sendo 4 lâminas de irrigação e 4 doses de paclobutrazol (PBZ). O sistema de irrigação utilizado foi a microaspersão, constituído de uma linha lateral para cada linha de plantas e dois microaspersores por planta. Em relação às análises nematológicas, cada amostra de solo $\left(250 \mathrm{~cm}^{3}\right)$ e raízes $(20 \mathrm{~g})$ foi analisada separadamente. Posteriormente, realizou-se a identificação de nematoides e a determinação dos níveis populacionais. O levantamento de fungos, bactérias e actinomicetos foi amostrado na profundidade de $0-30 \mathrm{~cm}$ para cada tratamento. Concluiu-se neste trabalho que se deve realizar um monitoramento permanente da população dos nematoides nas áreas produtoras de manga do Norte de Minas; sugere-se utilizar a lâmina de irrigação de $100 \%$ para um controle eficaz dos nematoides Criconemella sp. e Xiphinema sp., como também para a população de bactérias, onde recomenda-se utilizar a dose de $2,0 \mathrm{~g} / \mathrm{m} .1$. de PBZ; recomenda-se utilizar a dose de $1,5 \mathrm{~g} / \mathrm{m} .1$. de PBZ para o controle da maioria dos nematoides e a dose de 1,0 $\mathrm{g} / \mathrm{m} .1$. para o controle de Criconemella sp.; para os fungos e actinomicetos, os tratamentos avaliados não apresentaram valores médios satisfatórios, no entanto, evidenciam a necessidade de estudos adicionais na área em questão.

PALAVRAS-CHAVE: Regulador de crescimento, microaspersão, microbiota.

\section{EFFECT OF IRRIGATION DEPTHS AND PACLOBUTRAZOL DOSES IN SOIL MICROFAUNA CULTIVATED WITH MANGO CROP CV. HADEN IN MINAS GERAIS NORTH}

\begin{abstract}
This study aims to evaluate different irrigation depth and doses of a growth regulator on soil microbial population in mango crop cv. Haden in northern Minas Gerais. The experiment was carried out in a randomized design consisting of 16 treatments with three replications, with four irrigation depth and four doses of paclobutrazol (PBZ). The irrigation system used was microsprinkler, consisting of a lateral line for each row of plants and two microsprinklers by plant. With respect to nematodes analyzes, each soil
\end{abstract}




\section{EFEITO DE LÂMINAS DE IRRIGAÇÃO E DOSES DE PBZ NA MICROFAUNA DO SOLO CULTIVADO COM MANGUEIRA CV. HADEN NO NORTE DE MINAS GERAIS}

sample $(250 \mathrm{~cm} 3)$ and roots $(20 \mathrm{~g})$ was analyzed separately. Later, it was realized identification of nematodes and determination of the population levels. The survey of fungi, bacteria and actinomycetes were sampled at 0-30 cm depth for each treatment. It was concluded that should be to realize a permanent monitoring of the nematodes population in mango producing areas of northern Minas Gerais; it is suggested to use the $100 \%$ irrigation depth for an effective control of nematodes Criconemella sp. and Xiphinema sp. but also for bacteria population, where it is recommended to use a dose of $2.0 \mathrm{~g} / \mathrm{m} .1$. PBZ; recommended to use a dose of $1.5 \mathrm{~g} / \mathrm{m} .1$. PBZ to control nematodes majority and the dose of $1.0 \mathrm{~g} / \mathrm{m} .1$. to control Criconemella sp; for fungi and actinomycetes, the treatments did not show satisfactory average values, however, data make clear the necessity of additional studies in the area concerned.

\section{INTRODUÇÃO}

$\mathrm{Na}$ agricultura moderna há uma busca constante pelo aumento da produtividade utilizando da mecanização, irrigação, adubação química e aplicação de pesticidas. É necessário, portanto, o uso de sistemas agrícolas sustentáveis que não comprometa a qualidade do solo, tais como utilização de adubos orgânicos de qualidade e doses adequadas que melhoram as características físicas, químicas e microbiológicas do solo, sem que estes sejam afetados pelo manejo (PARKINSON et al., 1991; ANTOLÍN et al., 2005).

Dessa forma, a qualidade do solo influencia o potencial de uso, a produtividade e a sustentabilidade global do agroecossistema, sendo seu estudo necessário para fornecer informações sobre o manejo do solo e assegurar a tomada de decisões para uma melhor utilização desse recurso (SPOSITO \& ZABEL, 2003).

A diversidade de microrganismos é muito vasta sendo que as espécies identificadas vêm crescendo a cada ano sofrendo grande influência sazonal e sua sobrevivência é extremamente dependente de habitats específicos (WILSON, 1988; DORAN et al., 1996; ROSSELÓ-MORA \& AMANN, 2001; SMIT et al., 2001; TORSVIK \&
ØVREÅS, 2002; JOHNSON et al., 2003).

Os diferentes sistemas de cultivo promovem diferentes graus de mobilização do solo, causando alteração nas propriedades físicas e químicas que afetam os microrganismos, como por exemplo, bactérias, fungos, actinomicetos e nematoides. Estes organismos têm sido utilizados como bioindicadores $\mathrm{e}$ dependendo da sensibilidade, demonstram o estado da qualidade do solo (TURCO \& BLUME, 1999).

As populações de fauna do solo variam ao longo das estações do ano, havendo sempre a dominância de um organismo sobre outro, aonde este último pode não ser detectado na amostra (TORSVIK \& ØVREÅS, 2002). Tais variações estão diretamente ligadas ao regime hídrico, ao clima da região, à estrutura e manejo do solo, ao teor e à qualidade dos resíduos vegetais (DORAN et al., 1996; ROGERS; TATE III, 2001; TIEDJE et al., 2001).

Nesse sentido, a irrigação tornase imprescindível para a cultura da manga, principalmente nos primeiros meses após o plantio e nos períodos de estiagem para que as plantas tenham um desenvolvimento satisfatório no período de florescimento (CUNHA et al, 1994). Além disso, o cultivo da manga sob irrigação requer tecnologia apropriada e demanda altos investimentos tanto na implantação quanto na condução da 


\section{EFEITO DE LÂMINAS DE IRRIGAÇÃO E DOSES DE PBZ NA MICROFAUNA DO SOLO CULTIVADO COM MANGUEIRA CV. HADEN NO NORTE DE MINAS GERAIS}

cultura (ABANORTE, 2004). Sendo assim, a indução floral permite produzir mangas nos períodos citados promovendo o atendimento racional da demanda, sem ignorar os aspectos fitossanitários (GARCIA et al., 1994). A primeira ação no manejo da indução floral da mangueira cultivada nas condições climáticas do Norte de Minas Gerais é cessar o crescimento vegetativo, para que as gemas se diferenciem de vegetativas para florais ou para mistas, devendo para isso, que a planta esteja equilibrada nutricionalmente.

Em plantas na idade de produção, a partir do quarto ou quinto ano, recomenda-se irrigar durante $o$ período de escassez de chuvas e reduzir gradativamente a irrigação dois a três meses antes da época do florescimento, para que as plantas entrem em repouso vegetativo. Já durante a formação e desenvolvimento do fruto as irrigações devem ser frequientes, a fim de evitar a queda dos frutos recém-formados.

No início do período de estresse hídrico, sob irrigação localizada, recomenda-se que o fornecimento de água seja reduzido de maneira gradativa, uma vez que o volume de solo molhado é bastante pequeno e a densidade radicular bastante alta, de modo a condicionar a planta para o período de estresse hídrico pleno. Devese levar em consideração que o período de estresse hídrico é função da capacidade de retenção de água do volume de solo explorado pelas raízes da planta. Desse modo, os plantios situados em solos arenosos necessitam de menor período de estresse hídrico do que os plantios situados em solos argilosos (SOARES e COSTA, 1995).

Durante o período de estresse hídrico a água não deve ser suspensa totalmente, já que a planta necessita continuar fotossintetizando e acumulando reserva sem vegetar (ALBUQUERQUE et al., 1999). Por outro lado, a suspensão total da irrigação poderá contribuir para uma brotação vegetativa indesejada, caso haja chuva durante este período.

Simão (2004), estudando estratégias de manejo da irrigação de importantes fruteiras na região Norte de Minas, não encontrou diferenças significativas em todas as características avaliadas na cultura da manga nos dois primeiros anos após plantio, indicando que a necessidade hídrica das plantas foi suprida pelo tratamento que resultou em menor lâmina de água aplicada. O mesmo autor recomendou que fossem feitos estudos para essa cultura em estádios de desenvolvimento mais avançados.

A cultura da mangueira tem se expandido nas áreas irrigadas de Minas Gerais, principalmente nos perímetros do Jaíba e do Gorutuba. Dentre os sistemas de irrigação utilizados para a mangueira no Norte de Minas Gerais destaca-se a microaspersão, sendo $74 \%$ dos cultivos irrigados por este sistema de irrigação (ABANORTE, 2004).

As características edafoclimáticas da região Norte de Minas Gerais propiciam condições favoráveis para o desenvolvimento da cultura da mangueira, permitindo a produção de frutos de excelente qualidade com boa aceitação nos principais centros consumidores do país e no exterior, condição conferida à manga Haden.

A presença de vegetais é um importante fator na qualidade do solo, pelo fornecimento de fontes de energia necessárias à manutenção da população microbiana no solo (PASCUAL et al., 2000). A atividade agrícola predatória pode ter efeitos deletérios sobre a biodiversidade e os processos ecológicos do solo (ZILLI et al., 2003). 


\section{EFEITO DE LÂMINAS DE IRRIGAÇÃO E DOSES DE PBZ NA MICROFAUNA DO SOLO CULTIVADO COM MANGUEIRA CV. HADEN NO NORTE DE MINAS GERAIS}

Estudos têm mostrado a necessidade de relacionar a atividade enzimática com a microbiologia do solo de uma forma mais específica (DICK, 1997). A diversidade microbiana esta relacionada com a qualidade do solo. Daí a necessidade de estudos das atividades metabólicas destes microrganismos (TAYLOR et al., 2002). Métodos para estimar a atividade microbiana em solos da Região SemiÁrida são fundamentais no monitoramento ambiental. Sendo assim, o presente trabalho tem como objetivo avaliar diferentes lâminas de irrigação e doses de um regulador de crescimento (PBZ) na população microbiana do solo na cultura da manga cv. Haden no Norte de Minas Gerais.

\section{MATERIAL E MÉTODOS}

O experimento foi instalado em plantio comercial, localizado no Projeto de Irrigação Jaíba, município de Matias
Cardoso-MG. Segundo a classificação de Köppen o clima da região é do tipo Aw com chuvas de verão e períodos secos bem definidos no inverno.

Os resultados das análises física e fisico-hídrica do solo da área onde foi implantado o experimento são apresentados nas Tabelas 1, e 2, respectivamente.

Através dos resultados da análise física do solo, apresentada na Tabela 1 , o mesmo foi classificado como areia franca, segundo a metodologia para determinação das classes texturais dos solos descrita pela Comissão de Fertilidade... (1999). Em função desta classificação, será utilizada a tensão de 0,1 atm para a determinação da umidade correspondente à capacidade de campo do solo. Sendo o ponto de murcha do solo, a umidade correspondente a tensão de 15,0 atm.

Tabela 1 - Resultados da análise física do solo.

\begin{tabular}{|c|c|c|c|c|}
\hline $\begin{array}{l}\text { Profundidade } \\
\text { (cm) }\end{array}$ & $\begin{array}{l}\text { Matéria orgânica } \\
\left(\text { dag kg } \mathrm{kg}^{-1}\right)\end{array}$ & $\begin{array}{c}\text { Areia } \\
\left(\text { dag kg }^{-1}\right)\end{array}$ & $\begin{array}{c}\text { Silte } \\
\left(\text { dag kg }^{-1}\right)\end{array}$ & $\begin{array}{c}\text { Argila } \\
\left(\text { dag kg }^{-1}\right)\end{array}$ \\
\hline $0-20$ & 0,7 & 85 & 7 & 8 \\
\hline $20-40$ & 0,5 & 84 & 8 & 8 \\
\hline
\end{tabular}

Tabela 2 - Resultados da análise físico-hídrica do solo.

\begin{tabular}{ccccccccc}
\hline $\begin{array}{c}\text { Profundidade } \\
(\mathbf{c m})\end{array}$ & Unid. & $\mathbf{0 , 1}$ & $\mathbf{0 , 3}$ & $\mathbf{1 , 0}$ & $\mathbf{3 , 0}$ & $\mathbf{1 0 , 0}$ & $\mathbf{1 5 , 0}$ & Massa específica \\
\hline $0-20$ & $\%$ & 9,5 & 7,7 & 5,8 & 5,1 & 4,5 & 4,1 & 1,47 \\
$20-40$ & $\%$ & 12,2 & 9,1 & 7,0 & 6,3 & 5,6 & 5,3 & 1,44 \\
\hline
\end{tabular}

O experimento foi conduzido em delineamento inteiramente casualizado consistindo de 16 tratamentos com 3 repetições, sendo cada repetição constituída de 1 planta. Os tratamentos foram a combinação de 4 lâminas de irrigação (L1: 63\%, L2: 79\%, L3: 100\% e L4: $130 \%$ da lâmina padrão com intensidade de aplicação de 1,34 mm.h1) com 4 doses de paclobutrazol $(0,0$;
1,0; 1,5; e 2,0 gramas por metro linear de copa da mangueira).

O sistema de irrigação utilizado foi a microaspersão, constituído de uma linha lateral para cada linha de plantas e dois microaspersores por planta. Para o cálculo da lâmina padrão e do tempo de irrigação adotou o método FAO que corresponde à determinação da evapotranspiração potencial. A intensidade de aplicação na linha lateral 


\section{EFEITO DE LÂMINAS DE IRRIGAÇÃO E DOSES DE PBZ NA MICROFAUNA DO SOLO CULTIVADO COM MANGUEIRA CV. HADEN NO NORTE DE MINAS GERAIS}

utilizada na propriedade $\left(1,34 \mathrm{~mm} \cdot \mathrm{h}^{-1}\right)$ foi adotada como lâmina padrão (L3) para o cálculo das lâminas L1, L2, L4 e do tempo de irrigação. Como o tempo de irrigação e a intensidade de aplicação são os mesmos, diferentes lâminas foram aplicadas por diferença de vazão dos bocais dos emissores. A L1 foi calculada em $63 \%$ da lâmina considerada padrão, a L2 em $79 \%$, a L3 em $100 \%$ e a L4 130\%. O PBZ (Paclobutrazol) foi aplicado diretamente no solo em sulcos circulares com profundidade de 10 a $15 \mathrm{~cm}$ e de 60 a $70 \mathrm{~cm}$ de distância dos troncos das plantas. As doses de PBZ aplicadas foram: ausência do PBZ para a testemunha (P0); 1,0 g por metro linear de copa da mangueira (P1); 1,5 g por metro linear de copa da mangueira (P2) e 2,0 g por metro linear da mangueira (P3). As aplicações foram diluídas em dois litros de água, e as testemunhas (P0) receberam dois litros de água pura.

As análises nematológicas foram realizadas no Laboratório de Nematologia da Unidade Regional EPAMIG Norte de Minas (EPAMIG/URENM), Nova PorteirinhaMG.

Cada amostra de solo $\left(250 \mathrm{~cm}^{3}\right)$ e raízes $(20 \mathrm{~g})$ foi analisada separadamente pelo método de Jenkins (1964) e Coolen \& D'Herde (1972), respectivamente. Posteriormente, realizou-se a identificação de nematoides (MAI e MULLIN, 1996) e a determinação dos níveis populacionais.

As análises da microbiota (fungos, bactérias e actinomicetos) foram realizadas no Laboratório de Fitopatologia também da EPAMIG/URENM. O levantamento da microbiota do solo foi amostrado na profundidade de 0-30 $\mathrm{cm}$, para cada tratamento. Foram realizadas diluições seriadas utilizando $10 \mathrm{~g}$ de cada amostra de solo e três meios de culturas específicos para cada microrganismo, separadamente. Em seguida foi realizada contagem de colônias por placa.

\section{RESULTADOS E DISCUSSÃO}

O papel dos microrganismos nos processos funcionais de um ecossistema complexo como o solo pode ser facilitado através das análises da composição da comunidade microbiana (BORNEMAN et al., 2004).

Os resultados mostraram que tanto as doses de PBZ quanto as lâminas de irrigação, não influenciaram na população de actinomicetos. A microbiota do solo compete por oxigênio, recursos minerais e fontes de nutrientes, podendo causar a inibição desta por diversas formas de antagonismo (WELLER et al., 2002). Sendo esta uma possível explicação da inexistência de actinomicetos nos tratamentos avaliados (Figuras 1 e 2). Nesse contexto, cada solo possui características específicas como porosidade, textura, dentre outras, que podem influenciar diretamente na população de actinomicetos (ALABOUVETTE et al., 2006). Outra explicação é o baixo teor de matéria orgânica encontrado nas amostras de solo analisadas, considerado como a principal causa da pouca atividade microbiana em solos de regiões semiáridas, como o Norte de Minas (GARCIA et al., 1994). E por fim, outra possível causa da ausência dos actinomicetos nos tratamentos é a temperatura do solo que afeta diretamente a atividade microbiológica. Estudos demonstram que, geralmente, um aumento de $10^{\circ} \mathrm{C}$ dobra a atividade dos microorganismos até a temperatura ótima de cada espécie. Além disso, a temperatura do solo pode exercer efeitos na matriz do solo e no estado 


\section{EFEITO DE LÂMINAS DE IRRIGAÇÃO E DOSES DE PBZ NA MICROFAUNA DO SOLO CULTIVADO COM MANGUEIRA CV. HADEN NO NORTE DE MINAS GERAIS}

físico-químico dos contaminantes (BAKER e HERSON, 1994).

Quanto à população de bactérias, estas se mostraram as mais eficientes tanto na presença de doses de PBZ quanto nas diferentes lâminas de irrigação, apresentando maior população do que em relação aos fungos e actinomicetos (Figuras 1 e 2). A densidade populacional de bactérias não foi afetada com a aplicação dos parâmetros estudados, principalmente para as doses $0,1,0$ e 1,5 g por metro linear. Nos tratamentos com irrigação, a lâmina de $130 \%$ (L4) proporcionou maior desenvolvimento destes microrganismos. Isto se deve, provavelmente, à baixa quantidade de resíduos vegetais presentes nas parcelas do experimento.

Dentre os principais grupos de microrganismos presentes nos solos estão às bactérias, os actinomicetos, os fungos e nematoides. Grande parte da comunidade microbiana presente nos solos é formada pelas bactérias, tanto em quantidade de indivíduos quanto em variedade de espécies (MELLO, 2005). As bactérias geralmente participam ativamente de todas as transferências orgânicas importantes, para que o solo possa manter com sucesso os vegetais superiores, agindo diretamente nos solos por antibiose e competição (BRADY, 1989).

Apesar das bactérias serem mais eficientes na degradação de componentes orgânicos presentes nos solos, os fungos são mais resistentes às mudanças de condições ambientais tais como o pH e a salinidade (MELLO, 2005). Para estes, por sua vez, não foi observado um aumento expressivo de sua população em relação aos tratamentos aplicados (Figuras 1 e 2). Embora a influência dos fungos não seja ainda perfeitamente conhecida, sabe-se que desempenham um papel muito importante nas transformações dos constituintes do solo (BRADY, 1989). Os testes de identificação revelaram que quanto à natureza da população de fungos, esta foi bem homogênea no presente trabalho.

Em relação aos fitonematoides, nas avaliações realizadas foram encontrados os seguintes nematoides nas amostras de solo: Hemicycliophora sp., Xiphinema sp., Helicotylenchus sp., Criconemella sp. e Meloidogyne sp. Enquanto que, nas amostras de raízes, os nematoides Pratylenchus spp., Hemicycliophora sp., Criconemella sp. e Meloidogyne sp. foram encontrados parasitando a cultura da manga. Os dados da Tabela 3 verificam que Criconemella sp. apresentou maior população no solo em relação aos outros nematoides. A população de Xiphinema sp. foi encontrada na maioria dos tratamentos. Por ser um parasito de plantas perenes, sua presença é evidente tendo renome mundial. Lordello e $\mathrm{Da}$ Costa (1961) relataram declínio de plantios de manga na África do Sul, causado por Xiphinema brevicolle.

Tabela 3. População total dos microrganismos do solo cultivado com mangueira cv. Haden no Norte de Minas Gerais

\begin{tabular}{lllllllll}
\hline prat & hemi & xiphi & crico & heli & meloi & fung & bact & act \\
\hline 2210 & 1428 & 1036 & 2910 & 1601 & 147 & 9,12 & 286,24 & 0 \\
\hline
\end{tabular}

Como nematoide sedentário, o gênero Meloidogyne sp. é comum infectar a rizosfera de manga. Porém, a população de Meloidogyne sp. foi a menor encontrada neste trabalho. Apesar de Meloidogyne incognita ser considerado como parasita de manga, a ocorrência de infecção ainda é restrita 


\section{EFEITO DE LÂMINAS DE IRRIGAÇÃO E DOSES DE PBZ NA MICROFAUNA DO SOLO CULTIVADO COM MANGUEIRA CV. HADEN NO NORTE DE MINAS GERAIS}

(KHAN, et al. 2005). Concordando com Nazareno et al. (2010) que estudaram o efeito de matéria orgânica no solo e observaram que tanto Meloidogyne javanica quanto $M$. incognita apresentaram fator reprodutivo inferior a um. Foi observado que este nematóide foi menos afetado na sua capacidade reprodutiva, um indicativo de que dependendo da matéria orgânica usada, o mesmo pode apresentar capacidade de supressão. Esta ocorre em função das interações entre os nematóides, que dependem da densidade populacional de cada espécie presente na área e do tempo da associação (EINSEBACK,
1985). Da mesma forma que a matéria orgânica, o nitrogênio (N) (Tabela 4) também apresentou um valor baixo neste estudo (COMISSÃO DE FERTILIDADE..., 1999). Isto pode explicar a baixa população de Meloidogyne sp. na cultura da manga. Uma vez que, o $\mathrm{N}$ proporciona maior desenvolvimento do sistema radicular, considerado um macronutriente essencial para o desenvolvimento das plantas (SINCLAIR; HORIE, 1989). A atividade microbiana também pode ser altamente influenciada por fatores no solo como teor de umidade e temperatura do ar (ALEF, 1995).

Tabela 4. Resultado da análise química do solo

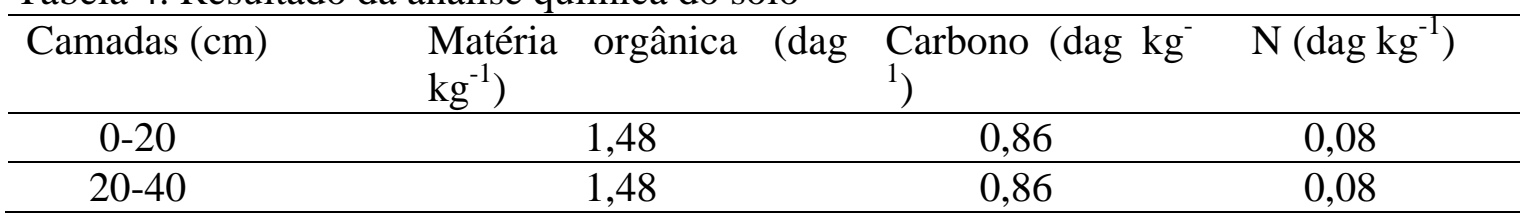

Matéria orgânica Método colorimétrico - Carbono Org. = M. Org./1,724

Nitrogênio calculado/Mat.Orgânica

Nas raízes, Pratylenchus spp. foi o principal nematoide encontrado parasitando a cultura, mesmo que sua população não tenha tido tanta representatividade. McSorlev et al. (1981) relata a ocorrência de Pratylenchus brachyurus parasitando plantios de manga.

Hemicycliophora sp. e Helicotylenchus sp. foram os nematoides encontrados em menor frequência em relação a Criconemella sp. Como nematoides de solos tropicais, estes foram relatados na cultura da manga. Sugere-se, portanto, um efetivo monitoramento nas áreas produtoras de manga desta região sendo necessário determinar a distribuição desses nematoides. Segundo McSorlev et al. (1981), Helicotylenchus dihystera foi mais abundante nas amostras de plantas jovens ( $<$ de 3 anos) do que nas plantas mais velhas (> 10 anos).
Quanto às doses de PBZ e as lâminas de irrigação (Figuras 1 e 2), observou-se que a população de Helicotylenchus sp. foi maior quando se aplicou a maior dose (P3), enquanto que as lâminas de irrigação mais efetivas sobre a população de nematoides foram L1 e L2.

Em relação à Criconemella sp., constatou maior efeito das doses P0 e $\mathrm{P} 2$ e das lâminas 1 e 4. A lâmina 3 exerceu maior efeito sobre a população de Hemicycliophora sp. seguido pela lâmina 1. Efeito contrário, ocorreu com Pratylenchus spp. nas raízes de manga. Os demais nematoides encontrados não demonstraram efeitos significativos dos tratamentos avaliados. Apenas Helicotylenchus sp. apresentou certa relação com a aplicação do fitoregulador (PBZ), onde a maior dose proporcionou aumento da população. $\mathrm{O}$ mesmo pode ter acontecido com as 


\section{EFEITO DE LÂMINAS DE IRRIGAÇÃO E DOSES DE PBZ NA MICROFAUNA DO SOLO CULTIVADO COM MANGUEIRA CV. HADEN NO NORTE DE MINAS GERAIS}

lâminas 1 e 2, as quais proporcionaram uma irrigação adequada para o desenvolvimento do nematoide. Segundo Badra e Khattab (1982), as populações de nematoides em solo e raízes nos cultivos de manga reduziram significativamente em função da aplicação do regulador de crescimento Ethephon.

A diminuição dos cultivos de manga devido ao ataque de nematoides tem sido relatada em varias regiões, principalmente nas cultivares Haden e Tommy (KHAN et al. 2005). Alguns nematoides encontrados neste trabalho têm sido associados a perdas econômicas nesta cultura, sendo esta uma verificação mundial atualizada dos resultados obtidos. As infestações de nematoides ocorrem em áreas principalmente onde a temperatura do ar é alta, neste caso com uma temperatura máxima anual de $35^{\circ} \mathrm{C}$, e com a presença de solos arenosos.

Deve-se salientar neste trabalho a estatística descritiva utilizada baseada em valores médios populacionais, considerando que para estudo de microrganismos, geralmente é utilizado este tipo de parâmetro, onde a amostra populacional não é distribuída uniformemente no ambiente.

Sabendo-se que os microrganismos são partes integrantes da qualidade do solo, é necessário um melhor entendimento da dinâmica e estrutura das comunidades microbianas. Nesse contexto, indicadores biológicos têm sido frequentemente usados para avaliar alterações na qualidade do solo pelo uso de diferentes práticas e sistemas de manejo.

Este trabalho foi mais uma etapa para uma melhor compreensão dos efeitos e interações de diferentes manejos sobre a comunidade microbiana do solo e assim, determinar meios para a recuperação do solo e, implementar práticas de manejo que poderão otimizar $\mathrm{o}$ ambiente microbiano do solo objetivando um aumento da produtividade e ao mesmo tempo, a sustentabilidade.

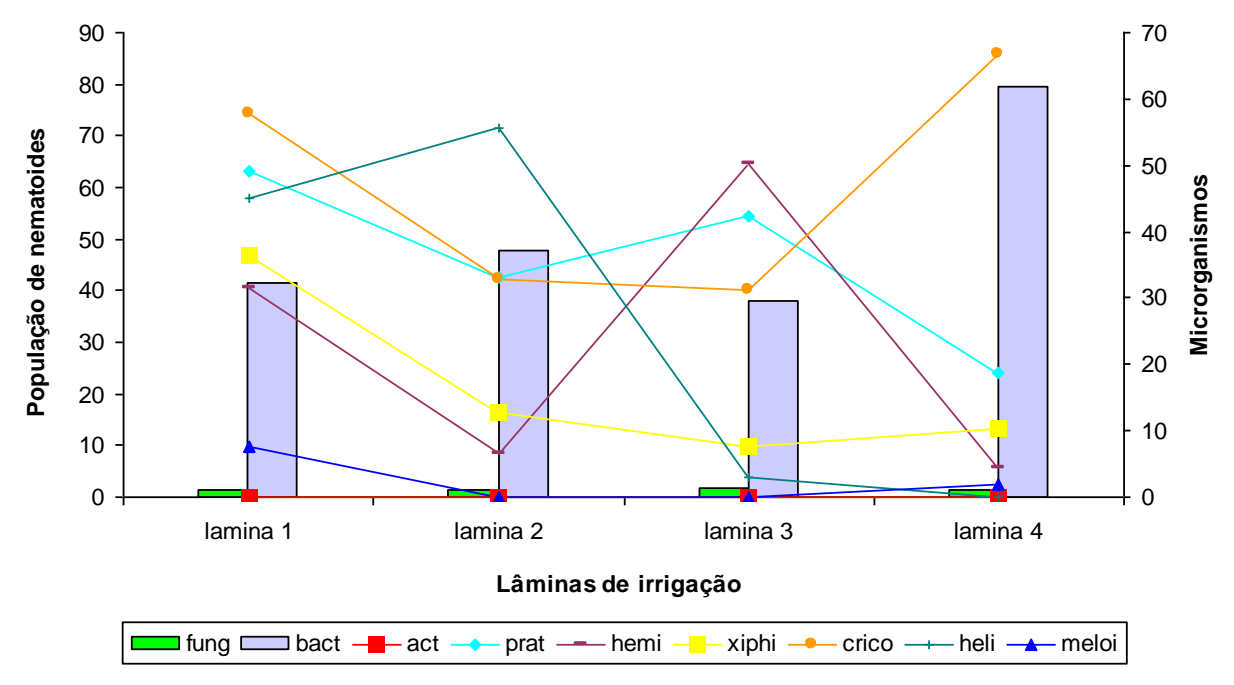

Figura 1. Efeito de lâminas de irrigação na população da microfauna do solo cultivado com mangueira cv. Haden no Norte de Minas Gerais 


\section{EFEITO DE LÂMINAS DE IRRIGAÇÃO E DOSES DE PBZ NA MICROFAUNA DO SOLO CULTIVADO COM MANGUEIRA CV. HADEN NO NORTE DE MINAS GERAIS}

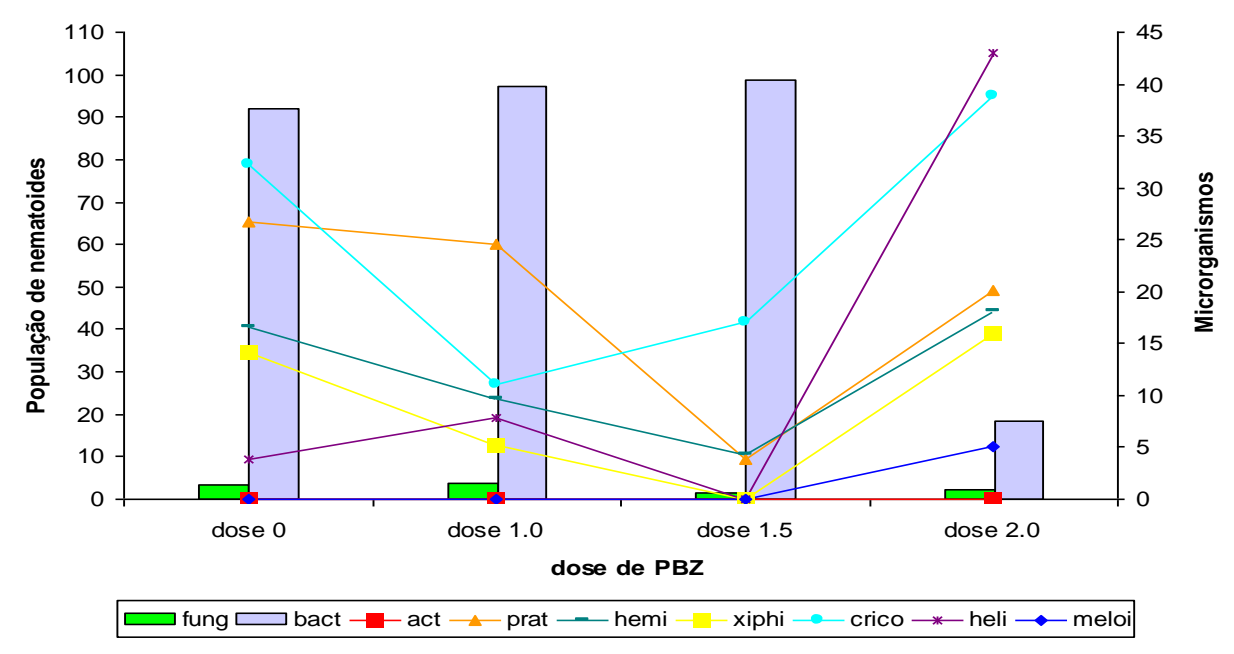

Figura 2. Efeito de doses de PBZ na população da microfauna do solo cultivado com mangueira cv. Haden no Norte de Minas Gerais

Nota: fung $=$ Fungos; bact $=$ Bactéria; act $=$ Actinomicetos; prat $=$ Pratylench $\boldsymbol{s} ;$ hemi $=$ Hemicycliophora; xiphi $=$ Xiphinema $; \quad$ crico $=$ Criconemella $;$ heli $=$ Helicotylenchus; meloi= Meloidogyne

\section{CONCLUSÕES}

Concluiu-se neste trabalho que:

- Deve-se realizar um monitoramento permanente da população dos nematoides nas áreas produtoras de manga do Norte de Minas

- Sugere-se utilizar a lâmina de irrigação padrão (100\%) para um controle eficaz do principal nematoide encontrado Criconemella sp. e para Xiphinema sp., como também para a população de bactérias, onde recomenda-se utilizar a dose de 2,0 g/m.l. de PBZ em regiões com semelhante condição edafoclimática.

- Recomenda-se utilizar a dose de 1,5 g/m.l. de PBZ para o controle da maioria dos nematoides encontrados e a dose de $1,0 \mathrm{~g} / \mathrm{m} .1$. para o controle de Criconemella sp.

- Para os fungos e actinomicetos, os tratamentos avaliados não apresentaram valores médios satisfatórios, no entanto, evidenciam uma dinâmica maior de estudos na área em questão.

\section{AGRADECIMENTOS}

Os autores agradecem a Fundação de Amparo à Pesquisa do Estado de Minas Gerais pelo financiamento do projeto.

\section{REFERÊNCIAS}

ALABOUVETTE, C., RAAIJMAKERS, J. M., NOTZ, R., DÉFAGO, G., STEINBERG, C., LEMANCEAU, P. Concepts and methods to assess the phytosanitary quality of soils. In: BLOEM, J.; HOPKINS, W. W.; BENEDETTI, A. (Eds.). Microbiological methods for assessing soil quality. Wallingford: CAB International, 2006. p. 257-269.

ALBUQUERQUE, J. A. S. de e MOUCO, M. A. do C. Efeitos, doses e aplicação do paclobutrazol em mangueira sob condições de alta temperatura do ar. In: CONGRESSO BRASILEIRO DE FRUTICULTURA, 16., 2000, Fortaleza, CE. Resumos... 


\section{EFEITO DE LÂMINAS DE IRRIGAÇÃO E DOSES DE PBZ NA MICROFAUNA DO SOLO CULTIVADO COM MANGUEIRA CV. HADEN NO NORTE DE MINAS GERAIS}

Fortaleza: Embrapa Agroindústria Tropical. SBF, 2000. CD-Rom.

ALEF, K. Soil respiration. In: ALEF, K.; Nannipieri, P. (Ed). Methods in applied soil microbiology and biochemistry. London: Academis Press, 1995. p. 214-219.

ANTOLÍN, M. C.; PASCUAL, I.; GARCÍA, C.; POLO, A.; SÁNCHEZDÍAZ, M. Growth, yield and solute content of barley in soils treated with sewage sludge under semiarid Mediterranean. Field Crops Res. 2005. 94: p. 124-237.

ASSOCIAÇÃO CENTRAL DOS FRUTICULTORES DO NORTE DE MINAS E SUDOESTE DA BAHIA (ABANORTE). Levantamento e estudo da cultura da manga para viabilização deste ramo de agronegócio no norte de Minas Gerais. Janaúba, Anais... Salvador, 2004. CD-ROM.

BADRA, T.; KHATTAB, M.M. Chemically-induced resistance to Rotylenchulus reniformis by ethephon growth regulation and relevant pathometabolites in mango seedlings. Nematologia Mediterranea,1982. cap. 10, p. 49-56.

BAKER, K. H.; Herson, D. S. Bioremediation. McGraw-Hill, Inc., Environmental Microbiology Associates, Inc. Harrisburg, Pennsylvania, 375 p, 1994.

BORNEMAN, J.; OLATINWO, R.; YIN. B.; BECKERS, J. O. An experimental approach for identifying microorganisms involved in specified functions: Utilisation for understanding a nematode suppressive soil. Australasian Plant Pathology, v. 33, n. 2, p. 151-155, 2004.
BRADY, N. C. Natureza e propriedade dos solos. 7. Ed. Rio de Janeiro: Freitas Bastos, 1989. 898 p.

RIBEIRO, A. C.; GUIMARÃES, P. T. G.; ALVAREZ V. H. V. Recomendações para o uso de corretivos e fertilizantes em Minas Gerais. 5 Ed. Viçosa, 1999. 359 p.

COOLEN, W. A.; D'HERDE, C. J. A meted for the quantitative extraction of nematodes from plant tissue. Ghrent, Belgian: State of Nematology and Entomology research Station, 1972, $77 \mathrm{p}$.

CUNHA, G. A. P.; SAMPAIO, J. M. M.; NASCIMENTO, A. S.; SANTOS FILHO, H. P.; MEDINA, V. M. Manga para exportação: Aspectos técnicos da produção. Brasília: EMBRAPASPI, 1994. 35 p.

DICK, R. P. Soil enzyme activities as integrative indicators of soil health. In: PANKHHURST, B. M.; DOUBE, B. M.; GUPTA, V. V. S. R. (Ed.). Biological indicators of soil health. Wallingford Oxon,: CAB International, 1997. cap. 6, p.121-156.

DORAN, J. W.; SARRANTONIO, M.; LIEBIG, M. A. Soil health and sustainability. Advances in Agronomy, v. 56, p. 2-54, 1996.

EINSEBACK, J. D. Interaction among concomitant populations of nematodes. In: SASSER, J. N.; CARTER, C. C. (Eds.). An advanced treatise on Meloidogyne. Biology and control. Raleigh: North Carolina State University Graphics, 1985. cap. 1, p.193-213.

GARCIA, C.; HERNANDEZ, T.; COSTA, F. Microbial activity soils under 


\section{EFEITO DE LÂMINAS DE IRRIGAÇÃO E DOSES DE PBZ NA MICROFAUNA DO SOLO CULTIVADO COM MANGUEIRA CV. HADEN NO NORTE DE MINAS GERAIS}

Mediterranean environmental conditions. Soil Biology and Biochemistry, v. 26, p. 1185-1191, 1994.

JENKINS, W.R. A rapid centrifugalflotation technique for separating nematodes from soil. Plant Disease Reporter, Washington, 1964, cap. 48, p. 292.

JOHNSON, M. J.; LEE, K. Y.; SCOW, K. M. DNA fingerprint reveals links among agricultural crops, soil properties, and the composition of soil microbial communities. Geoderma, v. 114, n. 3/4, p. 279-303, 2003.

KHAN, A.M.; SAYED, M.; SHAUKAT, S.S. Nematodes associated with mango in Sindh. International Journal of Biology and Biotecnology, v. 2, p. 217-919, 2005.

LORDELLO, L.G.E.; DA COSTA, C.P. A new nematode parasitic of Brasil, Biology, v. 21, p. 363-366, 1961

MAI, W. F.; MULlin, P. G. Plant parasitic nematodes: a pictorial key to genera. Ithaca: Cornell University Press, 1996, 277 p.

MCSORLEV, R.; PARRADO, J.L.; GOLDWEBER, S. Plant-parasitic nematodes associated with mango and realationship to tree condition. Nematropica, , v. 11, n. 1, p. 1-9, 1981.

MELLO, G. S. L. Avaliação da viabilidade da utilização do teste respirométrico de Bartha para determinar a biodegradação de hidrocarbonetos aromáticos polinucleares em solo tropical: caso do Fenantreno. 2005. 191 f Dissertação (Mestrado em Engenharia Hidráulica e Sanitária) - Universidade de São Paulo, São Paulo.
NAZARENO, G. G.; JUNQUEIRA, A. M. R.; PEIXOTO, J. R.; Efeito da matéria orgânica na multiplicação de nematóide das galhas em alface sob cultivo protegido. Biosci. v. 26, n. 4, p. 525-530, 2010.

PARKINSON, D.; GRAY, T. R. G.; WILLIAMS, S. T. Methods for studying the ecology of soil microorganisms. Oxford: Adlard, 1971. p. 116.

PASCUAL, J. A.; GARCIA, C.; HERNANDEZ, T.; MORENO, J. L.; ROS, M. Soil microbial activity as a biomarker of degradation and remediation process. Soil Biology and Biochemistry, v. 32, p. 1877-1883, 2000.

ROGERS, B. F.; TATE III, R. L. Temporal analysis of the soil microbial community along a toposequence in Pineland soils. Soil Biology and Biochemistry, v. 33, n. 10, p. 13891401, 2001.

ROSSELÓ-MORA, R.; AMANN, R. The species concept for prokaryotes. FEMS Microbiology Review, v. 25, n. 1, p. 39-67, 2001.

SIMÃO, F. R. Estudo de diferentes estratégias de manejo da irrigação de cinco importantes fruteiras na região Norte de Minas Gerais. 2004. 83 f. Dissertação (Mestrado em Engenharia Agrícola) - Universidade Federal de Viçosa, Viçosa.

SINCLAIR, T. R.; HORIE, T. Leaf nitrogen, photosynthesis, and crop radiation use efficiency: a review. Crop Science, v. 29, p. 90-98, 1989.

SMIT, E.; LEEFLANG, P.; GOMMANS, S.; Van DEN BROEK, J.; VAN, M. S.; WERNARS, K. Diversity 


\section{EFEITO DE LÂMINAS DE IRRIGAÇÃO E DOSES DE PBZ NA MICROFAUNA DO SOLO CULTIVADO COM MANGUEIRA CV. HADEN NO NORTE DE MINAS GERAIS}

and seasonal fluctuations of the dominant members of the bacterial soil community in a wheat field as determined by cultivation and molecular methods. Applied and Environmental Microbiology, v. 67, n. 5, p. 22842291, 2001.

SOARES, J. M.; COSTA, F. F. da. Informações técnicas sobre a cultura da manga no semi-árido brasileiro. EMBRAPA-CPATSA, Petrolina, p. 4379. 1995.

SPOSITO, G.; ZABEL, A. The assessment of soil quality. Geoderma, v. 114, n. 3/4, p. 143-144, 2003.

TAYLOR, J.P.; WILSON, B.; MILLS, M.S.; BURNS, R.G. Comparison of microbial numbers and enzymatic activities in surface soils and subsoils using various techniques. Soil Biology and Biochemistry, v. 34, p. 387-401, 2002.

TIEDJE, J. M.; CHO, J. C.; MURRAY, A.; TREVES, D.; XIA, B.; AHOU, J. Soil teeming with life: new frontiers for soil science. In: REES, R. M.; BALL,

B. C.; CAMPEBELL, C. D.; WATSON, C. A. Eds. Sustainable management of soil organic matter. Wallingford: CAB International, 2001. p. 393-412.
TORSVIK, V.; ØVREÅS, L. Microbial diversity and function in soil: from genes to ecosystems. Current Opinion in Microbiology, v. 5, n. 3, p. 240-245, 2002.

TURCO, R. F.; BLUME, E. Indicators of soil quality. In: SIQUEIRA, J. O; MOREIRA, F. M. S.; LOPES, A. S.; GUILHERME, L. G. R.; FAQUIN, V.; FURTINI NETO, A. E.; CARVALHO, J. G. Eds. Inter-relação fertilidade, biologia do solo e nutrição de plantas. Viçosa: SBCS; Lavras: UFLA/DCS, 1999. p. 529-549.

WELLER, D. M.; RAAIJMAKERS J. M; GARDENER B. B.; THOMASHOW, L. S. Microbial populations responsible for specific soil suppressiveness to plant pathogens. Annual Review of Phytopathology, v. 40, p. 309-348, 2002.

WILSON, E. O. The current state of biology diversity. In: WILSON, E. O. Eds. Biodiversity. Washington: National Academy Press, 1988. p. 3-18.

ZILLI， J. É.; RUMJANEK， N. G.; XAVIER, G. R.; COUTINHO H. L.DA C.; NEVES, M. C. P. Diversidade microbiana como indicador de qualidade do solo. Caderno de Ciência \& Tecnologia, cap. 20: p. 391-411, 2003. 